\title{
Sequence and analysis of the citrulline biosynthetic operon argC-F from Bacillus subtilis
}

\author{
Mary O'Reilly and Kevin M. Devine
}

Department of Genetics, Trinity College, Dublin 2, Ireland

\author{
Author for correspondence: Kevin M. Devine. Tel: +3531 7021872. Fax: +35316798558. \\ e-mail: kdevine@vax1.tcd.ie
}

\begin{abstract}
The citrulline biosynthetic operon argC-F located at $100^{\circ}$ on the Bacillus subtilis chromosome contains seven open reading frames which encode all the enzymes required for the biosynthesis of citrulline. The operon is transcribed as a single transcription unit. The second cistron of the operon is homologous to ArgJ (ornithine acetyltransferase) from Bacillus stearothermophilus and Neisseria gonorrhoeae, suggesting that the acetylation of glutamate and the deacetylation of acetylornithine are carried out by a single enzyme in a cyclical pathway. The argF gene is an orthologue of argf from Pseudomonas aeruginosa and a paralogue of arcB from $P$. aeruginosa and argFlargl from Escherichia coli.
\end{abstract}

Keywords: Bacillus subtilis, citrulline biosynthetic operon, $\arg C-F$
The citrulline biosynthetic operon $\arg C-F$ is located at approximately $100^{\circ}$ on the Bacillus subtilis chromosome between the loci met $D$ and trpS. A schematic diagram of the operon is presented in Fig. 1. The operon contains seven open reading frames (ORFs), $\arg C, \arg J, \arg B, \arg D$, $\operatorname{car} . A, \operatorname{car} B$ and $\arg F$, encoding all the enzymes required for the biosynthesis of citrulline. These were identified, with the exception of $\arg C$ and $\arg F$, by their homology with genes from Escherichia coli, Neisseria gonorrboeae and Bacillus stearothermophilus. This operon is transcribed as a single transcription unit. There are three overlapping ORFs $(\arg B / \arg D, \operatorname{car} A / \operatorname{car} B$ and $\operatorname{car} B / \arg F)$, suggesting that translation of these ORFs is coupled. The sequences of $\arg C$ and $\arg F$ were reported previously (Smith et al., 1990; Mountain et al., 1990), and our sequences concur with those reported.

It has been reported that DNA located between the $\arg C$ and $\arg B$ cistrons of this $B$. subtilis operon complements both $\arg A$ and $\arg E$ mutants of $E$. coli (Mountain et al., 1984, 1986). There is, however, only one ORF between the $\arg C$ and $\arg B$ cistrons in our sequence. The putative product of this ORF is $64 \%$ identical at the amino acid level to Arg J from B. stearothermophilus and $37 \%$ identical to the Arg J protein of Neisseria gonorrboeae (Fig. 2, Table 1; Martin \& Mulks, 1992; Sakanyan et al., 1993). The ArgJ protein is an ornithine acetyltransferase, an enzyme which uses acetylornithine (an intermediate in the citrul-

The EMBL accession number for the nucleotide sequence reported in this paper is Z26919. line biosynthetic pathway) as acetyl donor in the first reaction in the pathway, the acetylation of glutamate. Thus the acetylation of glutamate and the deacetylation of acetylornithine reactions in the biosynthesis of citrulline in B. subtilis appear to be carried out in a manner similar to that observed in B. stearothermophilus (Sakanyan et al., 1992, 1993) and N. gonorrboeae (Martin \& Mulks, 1992), and differently from that found in $E$. coli, where two separate enzymes, ArgA and ArgE, carry out the two reactions (Cunin et al., 1986).

The percentage amino acid identities between the ORFs from this operon and homologous proteins from $B$. subtilis and other organisms are shown in Table 1 . The percentage amino acid identities with homologues from $B$. stearothermophilus range from $51 \%$ (ArgB) to $64 \%$ $(\operatorname{ArgJ})$, and with homologues from $E$. coli from $33 \%$ (ArgB) to $42 \%$ (CarB). B. subtilis contains two carbamoyl phosphate synthetases, one involved in the biosynthesis of arginine (CarA, CarB, this work) and a second involved in pyrimidine biosynthesis (PyrAA, PyrAB, Quinn et al., 1991). These homologues are $48 \%$ (CarA, PyrAA) and $53 \%$ (CarB, PyrAB) identical (Table 1). The subunits of the two $B$. subtilis carbamoyl phosphate synthetases are more similar to each other than either is to the $E$. coli enzyme, suggesting that the gene duplication event in $B$. subtilis occurred after the divergence of Gram-negative and Gram-positive bacteria.

The Pseudomonas aeruginosa genome contains two genes encoding ArgF-like proteins, $\operatorname{argF}$ (Itoh et al., 1988) and $\operatorname{arcB}$ (Bauer et al., 1987), which appear to reflect an ancient 


\begin{tabular}{|c|c|c|c|c|c|c|c|}
\hline$P$ & $\arg C$ & argJ & $\arg B$ & $\arg D$ & carA & CarB & argF \\
\hline
\end{tabular}

Fig. 1. Schematic representation of the citrulline biosynthetic operon from $B$. subtilis. Each ORF is represented by a box. A gap between boxes indicates that the ORFs do not overlap; a single vertical line indicates that these ORFs do overlap. The operon promoter is represented by $\mathrm{P}$ and the putative arginine boxes recognized by the arginine repressor are indicated by triangles $(\triangle)$.

\begin{abstract}
B. SUBTIL
B. STEARO

N. GONORR

B. SUBTIL

B. STEARO

N. GONORR

M-IQLSEDQIVKVT-GDVSSPKGFQAKGVHCGLRYSKKDLGVI ISETPAVSAAVYTQSHF MTITKQTGQVTAVADGTVVTPEGFQAAGVNAGLRYSKNDLGVILCDVPASAAAVYTQSHF MAVNLTEKTAEQLPDIDGIALYTAQAGVKKPG--- HTDLTLIAVAAGSTVGAVFTTNRF

QAAPIKVTQDSLKHGPTLKAVIVNSAIANACTGEQGLKDAYTMRESFASQLGIEPELVAV QAAPLKVTQASLAVEQKLQAVIVNRPCANACTGAQGLKDAY EMRELCAKQFGLALHHVAV CAAPVHIAKSHLFDEDGVRALVINTGNANAGTGAQGR IDALAVCAAAARQIGCKPNQVMP **** *** *
\end{abstract}

B. SUBTIL

B. STEARO

N. GONORR

B. SUBTIL

B. STEARO

N. GONORR

B. SUBTIL

B. STEARO

N. GONORR

B. SUBTIL

B. STEARO

N. GONORR

B. SUBTIL

B. STEARO

N. GONORR

SSTGVIGEHLDMEKIHAGIELLKE- -TPAGSGDFEEAILTTDTVIKQTCYELAIGGK-TV ASTGVIGEYLPMEKIRAGIKQLVPGVTMADAEAFQTAILTTDTVMKRACYQTTIDGK-TV FSTGVILEPLPADK I IAALPKMQPAFWNEAA----RAIMTTDTVPKAASREGKVGDQHTV

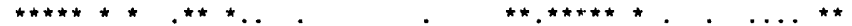

TIGGARKGSGMIHPNMATMLGFVTTDAAIEEKALQKALRETT'DVSFNQITVDGETSTNDM TVGGAAKGSGMIHPNMATMLAF ITTDANVSSPVLHAALRS ITDVSFNOITVDGDTSTNDM RATGIAKGSGMIHPNMATMLGFIATDAKVSQPVLQLMTQEIADETFNTITVDGDTSTNDS

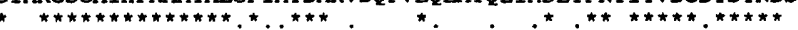

VLVMANACAENECLTE-DHPDWPVFKKALLLTCEDLAKEIARDGEGATKLIEAQVQGAKN VVMMASGLAGNDELTP-DHPDWENFYEALRKTCEDLAKOIAKDGEGATKLIEVRVRGAKT FVI IATGKNSOSEIDNI ADPRYAOLKELLCSLALELAQA IVRDGEGATKFITVRVENAKT

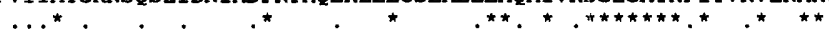

NLDANVIAKKIVGSNLVKTAVYGTDANWGRI IGAIGHSA-AQVTAEEVEVYLGGQCLFKDEEAKK IAKOIVGSNLVKTAVYGADANWGR I IGA IGYSD-AEVNPDNVDVA IGPMVMLKCDEAROAAYAAARSPLVKTAFFASDPNLGKRLAAIGYADVADLDTDLVEMYLDDILVAEH

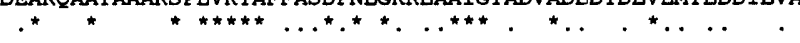

NNEPQPFSES IAKEYLEGDEITIVIKMAEGDGNGRAWGCDLTYDYIKINASYRT GSEPOPFSEEEAAAYLOOETVVI EVDLH IGDGVGVAWGCDLTYDYVKINASYRT GGRAASYTEAOGOAVMSKDEITVRIKLHRGOAAATVYTCDLSHGYVS INADYRS
Fig. 2. Alignment of the amino acid sequences of the ArgJ proteins from $B$. subtilis, (B. subtil) [this work] and $N$. gonorrhoeae ( $N$. gonorr) [Martin \& Mulks, 1992] and B. stearothermophilus (B. stearo) [Sakanyan et al., 1993] using the CLUSTAL V package (Higgins et al., 1992). Exact amino acid matches between all three proteins are indicated by an asterisk (*); conservative amino acid substitutions are indicated by a full stop (.).

Table 1. Percentage identity between the proteins encoded by the citrulline biosynthetic operon arg $C-F$ of $B$. subtilis and homologous proteins from other bacteria

\begin{tabular}{|c|c|c|c|c|c|c|c|}
\hline \multirow{3}{*}{$\begin{array}{l}\text { B. subtilis } \\
\text { argC-F } \\
\text { protein } \\
\text { ArgC }\end{array}$} & \multirow{3}{*}{$\frac{\left(\mathrm{F}_{\mathrm{op}}\right)^{*}}{(0 \cdot 22)}$} & \multicolumn{6}{|c|}{ Percentage identity with proteins from: } \\
\hline & & \multicolumn{2}{|c|}{$\begin{array}{c}\text { Gram-negative } \\
\text { bacteria } f\end{array}$} & \multicolumn{2}{|c|}{ B. subtilis } & \multicolumn{2}{|c|}{$\begin{array}{c}\text { B. stearo- } \\
\text { thermophilus }\end{array}$} \\
\hline & & $\operatorname{ArgC} C^{E c}$ & 37 & - & & $\operatorname{ArgC} \ddagger$ & 59 \\
\hline ArgJ & $(0 \cdot 30)$ & $\operatorname{Arg} J^{N g}$ & 37 & - & & ArgJ & 64 \\
\hline $\operatorname{Arg} B$ & $(0 \cdot 25)$ & $\operatorname{Arg} B^{\mathrm{Ec}}$ & 33 & - & & ArgB & 51 \\
\hline ArgD & $(0 \cdot 30)$ & $\operatorname{ArgD}{ }^{\mathrm{Ec}}$ & 38 & - & & $\operatorname{ArgD} \ddagger$ & 62 \\
\hline CarA & $(0 \cdot 23)$ & $\operatorname{CarA}^{\mathrm{Ee}}$ & 35 & PyrAA & 48 & - & \\
\hline CarB & $(0 \cdot 25)$ & $\mathrm{CarB}^{\mathrm{Ec}}$ & 42 & PyrAB & 53 & - & \\
\hline \multirow[t]{5}{*}{$\operatorname{ArgF}$} & $(0 \cdot 26)$ & $\operatorname{Arg} \mathrm{F}^{\mathrm{Pa}}$ & 47 & - & & - & \\
\hline & & $\mathrm{ArcB}^{\mathrm{Pa}}$ & 42 & & & & \\
\hline & & $\operatorname{Arg} F^{N g}$ & 42 & & & & \\
\hline & & $\operatorname{ArgF}{ }^{E c}$ & 40 & & & & \\
\hline & & $\operatorname{Arg} I^{\mathrm{Ec}}$ & 40 & & & & \\
\hline
\end{tabular}

* Frequency of optimal codon usage.

$\dagger \mathrm{Ec}, \mathrm{Ng}$ and $\mathrm{Pa}$ superscripts refer to proteins identified in E. coli, N. gonorrboeae and P. aeruginosa respectively.

$\ddagger$ Comparisons calculated using partial amino acid sequences. 
duplication event (the encoded proteins exhibit only $40 \%$ identity). The B. subtilis argF product is more similar to the $P$. aeruginosa $\operatorname{argF}$ product ( $47 \%$ identity) than it is to the $\operatorname{arc} B$ product ( $42 \%$ identity). Thus B. subtilis arg $F$ and $P$. aeruginosa arg $F$ appear to be orthologous genes, while the $P$. aeruginosa arc $B$ gene is paralogous. The E. coli $\arg F$ and $\arg I$ genes (whose products share $87 \%$ identity) represent a comparatively recent duplication in the E. coli lineage (Van Vliet et al., 1984) and both appear to be orthologues of $P$. aeruginosa arcB (with which they share $58 \%$ identity) rather than to $\operatorname{argF}$ ( $40 \%$ identity). Thus it appears that the B. subtilis argF and E. coli argF/argI are paralogues.

The extent of codon usage bias in the B. subtilis genes was estimated by the frequency of optimal codons $\left(\mathrm{F}_{\text {op }}\right.$, Table 1) as defined by Sharp et al. (1990). The values obtained are typical of moderately/lowly expressed genes in $B$. subtilis; the E. coli homologues have similarly moderately biased codon usage (data not shown).

\section{ACKNOWLEDGEMENTS}

This work was carried out as part of the CEC programme to sequence the entire genome of $B$. subtilis. The work was supported by EOLAS Scientific Grant SC/90/126 and by SCIENCE Grant SCI*0211-C(EDB). The authors would like to thank Pascale Serror (INRA, Jouy-en-Josas, France), Paul Sharp and Andrew Lloyd (Irish National Centre for Bioinformatics) for valuable assistance.

\section{REFERENCES}

Baur, H., Stalon, V., Falmagne, P., Luethi, E. \& Haas, D. (1987). Primary and quaternary structure of the catabolic ornithine carbamoyltransferase from Pseudomonas aeruginosa. Eur $J$ Biochem 166, 111-117.

Cunin, R., Glansdorff, N., Pierard, A. \& Stalon, V. (1986). Biosynthesis and metabolism of arginine in bacteria. Microbiol Rev 50, 314-352.

Higgins, D. G., Bleasby, A. J. \& Fuchs, R. (1992). Clustal v: improved software for multiple sequence alignment. CABIOS $\mathbf{8}$, 189- 191.

Itoh, Y., Soldati, L., Stalon, V., Falmagne, P., Terawaki, Y., Leisinger, T. \& Haas, D. (1988). Anabolic ornithine carbamoyltransferase of Pseudomonas aeruginosa: nucleotide sequence and transcriptional control of the arg $F$ structural gene. J Bacteriol 170, 2725-2734.

Martin, P. R. \& Mulks, M. H. (1992). Sequence analysis and complementation studies of the argJ gene encoding ornithine acetyltransferase from Neisseria gonorrboeae. I Bacteriol 174, 2694-2701.

Mountain, A., Mann, N. H., Munton, R. N. \& Baumberg, S. (1984). Cloning of a Bacillus subtilis restriction fragment complementing auxotrophic mutations in eight Escherichia coli genes of arginine biosynthesis. Mol \& Gen Genet 197, 82-89.

Mountain, A., McChesney, J., Smith, M. C. M. \& Baumberg, S. (1986). Gene sequence encoding carly enzymes of arginine biosynthesis within a cluster in Bacillus subtilis, as revealed by cloning in Escherichia coli. J Bacteriol 165, 1026-1028.

Mountain, A., Smith, M. C. M. \& Baumberg, S. (1990). Nucleotide sequence of the Bacillus subtilis argF gene encoding the ornithine carbamoyltransferase. Nucleic Acids Res 18, 4594.

Quinn, C. L., Stephenson, B. T. \& Switzer, R. L. (1991). Functional organisation and nucleotide sequence of the Bacillus subtilis pyrimidine biosynthetic operon. J Biol Chem 266, 9113-9127.

Sakanyan, V., Kochikyan, A., Mett, I., Legrain, C., Charlier, D., Piérard, A. \& Glansdorff, N. (1992). A re-examination of the pathway for ornithine biosynthesis in a thermophilic and two mesophilic Bacillus species. J Gen Microbiol 138, 125-130.

Sakanyan, V., Charlier, D., Legrain, C., Kochikyan, A., Mett, I., Piérard, A. \& Glansdorff, N. (1993). Primary structure, partial purification and regulation of key enzymes of the acetyl cycle of arginine biosynthesis in Bacillus stearotbermophilus: dual function of ornithine acetyltransferase. J Gen Microbiol 139, 393-402.

Sharp, P. M., Higgins, D. G., Shields, D. C., Devine, K. M. \& Hoch, J. A. (1990). Bacillus subtilis gene sequences. In Genetics and Biotechnology of Bacilli, vol. III, pp. 89-98. Edited by M. M. Zukowski, A. T. Ganesan \& J. A. Hoch. New York: Academic Press.

Smith, M. C. M., Mountain, A. \& Baumberg, S. (1990). Nucleotide sequence of the Bacillus subtilis argC gene encoding the $\mathrm{N}$ acetylglutamate-gamma-semialdehyde dehydrogenase. Nucleic Acids Res 18, 4595.

Van Vliet, F., Cunin, R., Jacobs, A., Piette, J., Gigot, D., Lauwerreys, M., Piérard, A. \& Glansdorff, N. (1984). Evolutionary divergence of genes for ornithine and aspartate carbamoyltransferases complete sequence and mode of regulation of the Escherichia coli argF gene; comparison of argF with argI and pyrB. Nucleic. Acids Res $12,6277-6289$.

Received 1 November 1993; accepted 1 December 1993. 